\title{
Does Sport Event Involvement Influence Brand Recognition of Official Sponsors and Ambush Marketers?
}

Authors' contribution:

A) conception and design

of the study

B) acquisition of data

C) analysis and interpretation

of data

D) manuscript preparation

E) obtaining funding

\author{
Monika Piątkowska ${ }^{\text {A,C-E }}$, Sylwia Gocłowska C,D
}

Józef Pitsudski University of Physical Education in Warsaw, Poland

ABSTRACT

The main aim of the study is to verify how event involvement in the UEFA Euro 2012 influenced the recognition of both sponsors' and ambushers' brands. ComputerAssisted Personal Interviews were conducted on a representative sample of the Polish society $(\mathrm{N}=1,000)$. On the basis of five groups of consumers regarding involvement in the event, authors examined brand recognition, using Top of Mind Awareness (TOMA) tests of official sponsors and ambushers.

The highest TOMA rate was observed in the group of heavy viewers. The lower the quantity and intensity of the matches watched, the lower the percentage of people who recalled a brand of the official sponsor at first. An inverse relationship exists in the case of people who identified the ambush marketers.

Ambush marketing phenomenon does not seem to threaten official sponsors of the event among consumers involved in the event. Therefore, it seems to be crucial to take into account the division between fans and non- fans of the event and level of their event involvement whilst measuring brand recognition.

It is noticeable that in the current literature the issue of effects of ambushing on consumers divided into groups of fans and non-fans has been largely ignored. Thus this study shows how important conducting a test of brand recognisability based on involvement of consumers in the sport event is.

KEYWORDS $\quad$ sponsorship, ambush marketing, brand recognition, event involvement, EURO 2012

\section{Introduction}

Although the issue of ambush marketing is an area of increasing interest for researchers of sports sponsorship (Dickson, Naylor, Phelps, 2015; Ellis, Parent, \& Seguin, 2016; McKelvey, \& Burton, 2016; McKelvey, \& Longley, 2015; Piątkowska, Żyśko and Gocłowska, 2015), there is a noticeable deficit of scientific research regarding factors determining the faultless brand recognition of the sponsor of the sport event. The subject literature has pointed out that ambush marketer misidentification occurs when "consumers incorrectly believe that an ambush marketer that does not officially support an event is an official sponsor of that event" (Wolfsteiner et al., 2015, p. 138).

When measuring brand awareness and recognition in terms of the effectiveness of sponsorship, it is necessary to look at the factors that influence them. Shani and Sandler (1998) argue that ambush marketing can only be effective if consumers are not well informed about official sponsorship rights and are not familiar 
with different ambush marketing strategies. Other researchers have identified various aspects that influence the results of brand recognition tests. It is believed that associating a sponsor's brand with a sporting event is a key factor when it comes to recognizing and recalling that brand or a sponsor's product (Grohs et al., 2004). It is crucial to create successful event campaigns, they need to have a strong association with the event (Wolfsteiner et al., 2015). Equally important factors are: the exposition of an event that features in the mass media and market prominence, the intensity of advertising campaigns for a sponsor's brand, the brand's current popularity (Crompton, 2004), and the prior knowledge of a brand (Boshoff, \& Gerber, 2008).

But the biggest influence on a consumer's recognition of a sponsor's brand is the extent to which consumers are committed to a sport event, as well as their attention, focus on, and interest in a given sport (Meenaghan, 2001). Researchers call that event involvement which indicates increased significance of an object and is reflected in greater knowledge of a domain, such as a sport, and/or a boosted level of enthusiasm for a property, such as a sports event (Lardinoit, \& Derbaix, 2001). Event involvement should be differentiated distinctly from fan identification, which is based on three elements: an individual's personal commitment to, perceived connectedness with, and self-categorization as a fan of a sports team. It results from attributed biases toward his or her own team (in-group) and against opposing teams (out-group); (Wann, \& Dolan, 1994). Researchers have also proven that high levels of consumer involvement in an event positively influence the results of brand awareness and recognition tests pertaining to a sponsor (Meenaghan, 2001). Pham (1992) argues that at low levels of event involvement, the event as a whole and, thus, stimuli occurring in the event receive little attention. An increase in event involvement leads to higher attention paid to the event and to related stimuli. Such active information search and information processing (Laurent, \& Kapferer, 1985) can result in a better understanding of and differentiation among official sponsors and ambush marketers. It also enables consumers to eliminate non-sponsoring companies. On the other hand, the research conducted by Wolfsteiner, Grohs and Wagner (2015) shows that event involvement has no effect on ambush marketer misidentification. Event involvement has a positive influence on both official sponsor identification and ambush marketer misidentification simultaneously. Therefore, we see the level of involvement becomes a crucial factor in determining sponsorship effectiveness and needs to be tested in depth.

It can be assumed that consumer involvement in a sport event consists of, above all else, either watching sport programs or direct participation in an event in which consumers show a high level of concentration and interest. This results in them noticing sport event sponsors. Therefore, the authors made an attempt to understand the factors that may lead to misidentification of official sponsors and to verify how event involvement in the UEFA Euro 2012 influenced the recognition of both sponsors' and ambushers' brands.

\section{Methodology}

\section{Data collection procedure}

A survey was conducted from 19 July to 23 July 2012 (18 days after the final match of UEFA Euro 2012) by means of CAPI technique (Computer Assisted Personal Interview). The survey comprised a representative random sample of 1,000 Poles above the age of 15 years. The respondents were contacted personally and selected from a personal identification number frame run by the Department of the State Central Register and Computer Networks of the Ministry of the Interior and Administration.

Stratification included nine macroregions and seven different classes of town sizes. As a result of crossing the macroregions with the classes of town size, 55 strata were obtained, out of which 170 municipalities were drawn. These formed the basis on which addresses were drawn. Municipalities were drawn with a probability proportional to the number of their residents aged 15 years and older. An independent drawing of addresses was held from among 170 municipalities. Six face-to-face interviews were conducted in each of the municipalities drawn. The selection of respondents was carried out using the Kish grid, which ensures that every family member in the household drawn had the same chance of being interviewed. 
Analysis of the distribution of variables revealed four respondents whose responses significantly departed from the rest in terms of the quantity and intensity of the matches watched during the UEFA Euro 2012. Entries with no data were removed $(n=165)$. Table 1 presents the characteristics of the study population $(n=831)$.

\section{Data analysis procedure}

In order to evaluate the brand recognition of official sponsors and ambush marketers, in different groups we adopted a typology of consumer behaviour during the UEFA Euro 2012 (Piątkowska, Gocłowska and Żyśko, 2015). We conducted a hierarchical clustering that adopted a Euclidean metric in order to divide the population into homogeneous groups according to two psychographic variables: the quantity and intensity of the matches watched.

As for quantity the respondents were asked: The 2012 UEFA European Championship was co-hosted by Poland and Ukraine in June. Have you watched any Euro 2012 matches? If so, how many did you see? The question about intensity was posed as: Please think about the matches you watched within the 2012 UEFA European Championship. Did you watch them entirely or only fragments?

Table 1. Characteristics of the examined population

\begin{tabular}{lcc}
\hline Factors & $(\boldsymbol{n}=\mathbf{8 3 1})$ & \\
\hline Gender & $\mathrm{n}$ & $\%$ \\
Men & 447 & 54.0 \\
Women & 381 & 46.0 \\
Age & & \\
15-29 & 251 & 30.2 \\
30-39 & 146 & 17.5 \\
40-49 & 137 & 16.5 \\
50-59 & 151 & 18.1 \\
60 and older & 147 & 17.7 \\
Education & & \\
elementary & 136 & 16.4 \\
basic vocational & 238 & 28.7 \\
secondary & 309 & 37.2 \\
higher & 147 & 17.7 \\
Place of residence & & \\
rural area & 322 & 38.8 \\
town or city up to 20,000 residents & 94 & 11.3 \\
city 21,000-50,000 residents & 94 & 11.3 \\
city 51,000-99,000 residents & 79 & 9.5 \\
city 101,000-199,000 residents & 80 & 9.6 \\
city 200,000-500,000 residents & 72 & 8.7 \\
city >500,000 residents & 89 & 10.7 \\
\hline Soure: 0wn study. & &
\end{tabular}

Source: own study.

As a result, we obtained five groups of the UEFA Euro 2012 consumers, regarding involvement in the event: heavy viewers $(n=203)$, moderate viewers $(n=115)$, light viewers $(n=175)$, very light viewers $(n=$ 257), and non-viewers $(\mathrm{n}=82)$.

In testing the brand recognition of official sponsors and ambush marketers during the UEFA Euro 2012, we adopted basic marketing communication criteria measuring the extent to which a brand is recalled by consumers, i.e., measuring brand awareness in the researched population: Top of Mind (TOMA), Unaided (UBA) and Aided Brand Awareness (ABA). This paper presents only TOMA rate - the percentage of consumers who spontaneously name a specific brand first. The respondents were asked: Do you know what brand/ company was the official sponsor of UEFA Euro 2012? Please name all the sponsors who come to your mind. 
The statistics were calculated using the $\mathrm{IBM}^{\circledR}$ SPSS $^{\circledR}$ Statistics version 21 program. The chi-square test of independence was performed for consumers to verify statistically significant differences between the measures of brand awareness of official sponsors and ambushers. The $P$-value for statistical significance is .05 .

\section{Results}

Table 2 shows the results of TOMA brand recognition tests of companies running promotional campaigns during the UEFA Euro 2012. The results of a chi-square test of independence demonstrated that the affiliation to a group influences brand recognition of UEFA Euro 2012 official sponsors $(\chi 2=198.7$, $\mathrm{p}<.001)$. The highest TOMA rate was observed in the group of heavy viewers $(59.8 \%)$. It was much higher than in the other groups: moderate viewers $(\chi 2=14.93, \mathrm{p}<.01)$, light viewers $(\chi 2=20.76, \mathrm{p}<.01)$, very light viewers $(\chi 2=110.47, \mathrm{p}<.01)$, and non-viewers $(\chi 2=215.04, \mathrm{p}<.001)$. When analysing each group, a downward tendency can be observed: the lower the number of the watched matches, the lower the percentage of people who recalled a brand of the official sponsor as first. In the group of non-viewers, one in five respondents (19.8 $\%)$ correctly identified the official sponsor. The same rule applies to a test of brand awareness in each sponsorship category (EUROTOP, EURO sponsors, and national sponsors) in which the TOMA metric was adopted.

Table 2. Brand recognition according to the TOMA metric of companies running promotional campaigns during the UEFA Euro $2012(\%)$

\begin{tabular}{|c|c|c|c|c|c|}
\hline \multirow[t]{2}{*}{ Category } & \multicolumn{5}{|c|}{ TOMA metric $(\%)$} \\
\hline & 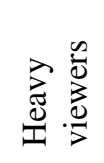 & 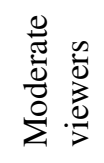 & 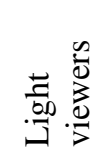 & 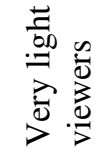 & 它 \\
\hline Sponsors, including: & $59.8^{\mathrm{a}}$ & $47.9^{\mathrm{b}}$ & $45.9^{\mathrm{c}}$ & 29.6 & 19.8 \\
\hline EUROTOP & 48.5 & 39.3 & 40.1 & 23.3 & 13.6 \\
\hline EURO sponsors & 7.8 & 6.8 & 5.2 & 5.1 & 4.9 \\
\hline National sponsors & 3.4 & 1.7 & 0.6 & 1.2 & 1.2 \\
\hline Ambushers & $20.6^{\mathrm{a}}$ & 26.5 & 30.8 & $37.4^{\mathrm{d}}$ & 25.9 \\
\hline Don't know/don't remember & $18.1^{\mathrm{a}}$ & $22.2^{\mathrm{b}}$ & $21.5^{\mathrm{c}}$ & 30.0 & 54.3 \\
\hline
\end{tabular}

significantly different $p<.05-{ }^{\mathrm{a}}$ heavy viewers vs. other groups ${ }^{\mathrm{b}}$ moderate viewers vs. very light and non-viewers;

${ }^{\mathrm{c}}$ light vs. very light viewers; ${ }^{\mathrm{d}}$ heavy viewers vs. other groups; ${ }^{\mathrm{d}}$ very light vs. moderate and light viewers

Source: own study.

An inverse relationship exists in the case of people who had to identify the ambush marketers. In the group of heavy viewers, the TOMA rate of ambushers was $20.6 \%$. It is much lower than in the other groups: moderate viewers $-26.5 \%(\chi 2=7.39, \mathrm{p}<.01)$, light viewers $-30.8 \%(\chi 2=20.8, \mathrm{p}<.01)$, and very light viewers $-37.4 \%\left(\chi^{2}=51.78, \mathrm{p}<.01\right)$. In the case of non-viewers, one-fourth of the respondents misidentified the ambushers, but it can be clearly seen that in this group the respondents were unaware of who the official sponsor was and who was not. More than a half of the respondents (54.3\%) of this group did not know or did not remember any brand connected with the analyzed event. This result is much lower than that of heavy viewers $(\chi 2=207.66, p<.01)$ and moderate viewers $(\chi 2=155.79, p<.01)$.

Table 3 presents recognition of five brands perceived as the UEFA Euro 2012 official sponsors. In the test conducted within the groups of consumers the TOMA metric was adopted. Due to a high percentage of respondents in each segment who did not know or did not remember any brand connected with the UEFA Euro 2012, analysis was conducted on a group of people who recalled any brand. Affiliation to a segment is a factor that influences brand recognition of the sponsors and ambushers $(\chi 2=195.066, \mathrm{p}<.001)$. 
Table 3. Brand recognition test of companies running promotional campaigns during the UEFA Euro 2012 conducted among different groups of consumers according to the TOMA metric (\%)

\begin{tabular}{clllll}
\hline & & & & \\
& & &
\end{tabular}

Brand names of sponsors of UEFA Euro 2012 are in bold.

Source: own study.

The results presented in table 3 confirm the assumptions. In the group of heavy viewers, the official sponsors from the EUROTOP category achieved the highest brand recognition rates: Kia, Coca-Cola, and McDonald's. Leading ambush marketers also placed high in the ranking: Biedronka, and a representative of the brewing industry, Tyskie, which exceeded its competitor Carlsberg by $1.2 \%$. Similar results were noted in the groups of moderate and light viewers. More than one-fourth of the respondents recalled Coca-Cola (26.4 $\%$ and $25.9 \%$, respectively), followed by Biedronka ( $18.7 \%$ and $20.7 \%$, respectively, according to the TOMA metric). In the groups of very light and non-viewers, Biedronka was most often associated with the event (26.1 $\%$ and $35.1 \%$, respectively) outstripping the other mentioned brands by a dozen or so percentage points. In both groups ambush marketers placed high in the ranking: Tyskie (14.4\% and $10.8 \%$, respectively) and Warka ( $7.2 \%$ and $10.8 \%$, respectively), which were competitors to Carlsberg.

\section{Discussion}

In addition to measuring brand recognition, many researchers also try to observe which personal traits of consumers influence brand recognition. Researchers claim that respondents' answers result from their involvement in the event. Similar results were obtained in the research derived from this study. The rate of brand awareness was the highest in the groups of consumers who watched the greatest number of matches and whose involvement was high. Almost $60 \%$ of heavy viewers recognized the sponsors. This rate decreases proportionally with the number of matches watched and the involvement in the sport event. Less than $20 \%$ of non-viewers, according to the TOMA metric, identified the official sponsors of the UEFA Euro 2012. Considering brand awareness measured in each segment by means of TOMA, the first three brands that heavy viewers recalled were the official sponsors, whereas non-viewers correctly identified only one. Biedronka was misidentified as the official sponsor only in the groups of very light viewers and non-viewers. Similar results were obtained through a research conducted during FIFA World Cup 2002 (Ko et al., 2008). Respondents who were more involved in the sport event performed better when identifying the official sponsors. The results they obtained provide strong evidence that spectators' sports involvement plays an important role in predicting their awareness of sponsor. Kinney et al. (2008) also documented that the involvement in the NASCAR racing explained $12 \%$ of the adjusted variance in total sponsor recall scores.

Sandler and Shani (1989) achieved a similar result. Researchers state that consumer confusion about the official sponsors and ambushers during the Winter Olympics in Canada in 1998 was high. Official sponsors were recognized by $20 \%$ of respondents per the UBA measure; $39 \%$ per the ABA measure. The authors segmented the respondents according to the number of matches watched. Brand recognisability of the official sponsors in each segment presents as follows: UBA measure among light viewers $-18.9 \%$, moderate viewers $-33.5 \%$, and heavy viewers $-37.5 \%$; ABA measure among light viewers $-37 \%$, moderate viewers $-46 \%$ and heavy viewers $-52.2 \%$. 
On the other hand, Wolfsteiner, Grohs and Wagner (2015) proved that event involvement has no effect on ambush marketer misidentification. Their study was based on experiments, they used fictitious press releases, drawings and pictures to inform respondents about different ambush marketing strategies during the developed fictitious sports events. During the experiment, authors showed two real company names that served as the official sponsor and ambush marketer. Authors asked about consumer involvement using only one question which was not related to numbers of matches watched or involvement during watching. The statement to the consumer was "I am very interested in the event name". Using fictitious press releases, drawings and pictures during the fictitious event and lack of questions related do matches or games watched can be the reason why Wolfsteiner, Grohs and Wagner (2015) results are not similar to other studies. Thus, authors of this study suggest that it is necessary to categorize consumers and pay attention to accurately grasp consumer involvement in the event.

It can be assumed that spectator involvement in a sport event reflects their interest in the event which, as a consequence, helps the spectators notice and remember the sponsors of an event

\section{Conclusions}

Most of the studies available in the subject literature on ambush marketing deal with explaining the phenomenon of ambush marketing, its classification and methods as well as legal and ethical considerations. It is noticeable that the issue of effects of ambushing on consumers has been largely ignored. Given the aims of both ambushers and official event sponsors, there is a clear need that academic researchers need to address. Consequently, the research presented sets out to examine the impact ambush marketing can have on various groups of consumers.

The research results confirm the hypothesis that sport event involvement influences brand recognition of official sponsors and ambushers. Higher levels of event involvement decrease ambush marketer misidentification in case of Polish consumers during UEFA Euro 2012. Therefore, it seems to be crucial to take into account dividing between fans and non- fans of the event and level of their event involvement while measuring brand recognition of companies carrying promotional campaigns during any sport event. Presenting data of brand awareness among consumers who are completely not interested in the event and do not identify with it may underestimate the recognition rates. The advertising message does not reach the non-fan audience as they are not a target group of the promotional campaign designed by sponsors and may easily misidentify them with ambushers.

The ambush marketing phenomenon does not seem to threaten official sponsors of the event among consumers involved in the event. Even though high TOM rates of ambushers' brand were found in non-fans those who do not identify themselves with the event - those brands may be regarded as any brands carrying out promotional campaigns and communicating with the audience but they do not reach the association with the event. Therefore, the aim of future research should be to focus on more effective means of addressing the ambushing threat in the involved groups of fans.

It has already been proven that effective strategic positioning of official sponsor brands, allied to better targeting of and engagement with consumers, may provide a competitive defence against ambushing. However, further research is needed in this regard; moreover, given the rise of social media, new and different ambushing challenges are emerging. It seems necessary, in the context of a better understanding of cognition and behavior in this field, that researchers, event owners and official sponsors begin to formulate and implement measures that directly account for consumer responses to official sponsorships and to ambush marketing. 


\section{Acknowledgments}

This paper was prepared under the statutory framework of Josef Pilsudski University of Physical Education in Warsaw DS. 232 - "Sport consumption styles of the Poles", financed by the Ministry of Science and Higher Education in Poland.

\section{REFERENCES}

Boshoff, C., \& Gerber, C. (2008). Sponsorship recall and recognition: The case of the 2007 Cricket World Cup, South African Journal of Business Management, 39(2), 1-8.

Crompton, J.L. (2004) Conceptualization and alternate operationalizations of the measurement of sponsorship effectiveness in sport, Leisure Studies, 23(3), 267-281.

Dickson, G., Naylor, M., \& Phelps, S. (2015). Consumer attitudes towards ambush marketing. Sport Management Review, 18(2), 280-290.

Ellis, D.L., Parent, M.M., \& Seguin, B. (2016) Olympic Ambush Marketing Networks and Knowledge Transfer: Examining Their Impact on the Institutionalization of Anti-Ambush Marketing Legislation. Journal of Sport Management, 2016, 30(5), 473-489. DOI: 10.1123/jsm.2015-0205.

Grohs, R., Wagner, U., \& Vsetecka, S. (2004). Assessing the effectiveness of sport sponsorships - an empirical investigation, Schmalenbach Business Review (SBR),56(2), 119-138.

Kinney, L., McDaniel, S.R., \& Degaris, L. (2008). Demographic and psychographic variables predicting NASCAR sponsor brand recall, International Journal of Sports Marketing and Sponsorship, 9(3), 169-179.

Ko, Y.J., Kim, K., Claussen, C.L., \& Kim, T.H. (2008). The effects of sport involvement, sponsor awareness and corporate image on intention to purchase sponsors' products, International Journal of Sports Marketing and Sponsorship, 9(2), 7994.

Lardinoit, T., \& Derbaix, C. (2001). Sponsorship and recall of sponsors, Psychology and Marketing, 18(2), 167-190.

Laurent, G., \& Kapferer, J.N. (1985). Measuring consumer involvement profiles, Journal of Marketing Research, 22(1), 41-53. DOI: $10.2307 / 3151549$.

McKelvey, S. \& Burton, N. (2016). Who owns Games? Time to retire term 'ambush marketing'. Street \& Smith's Sportsbusiness Journal, 19(18), 23.

McKelvey, S., \& Longley, N. (2015). Event-specific ambush marketing legislation for mega-sporting events: an economics perspective. International Journal of Sports Marketing \& Sponsorship, 16(5), 20-28.

Meenaghan, T. (2001). Understanding Sponsorship Effects, Psychology \& Marketing, 18, 95-122.

Pham, M.T. (1992). Effects of Involvement, Arousal, and Pleasure on the Recognition of Sponsorship Stimuli, Advances in Consumer Research, 19(1), 85-93.

Piątkowska, M., Gocłowska, S., Żyśko, J.(2015). Typology of consumer behaviors during the 2012 UEFA European Championships, Baltic Journal of Health and Physical Activity, 7(3), 39-50.

Piątkowska, M., Żyśko, J., \& Gocłowska, S. (2015). A Systematic Literature Review on Ambush Marketing in Sport, Physical Culture and Sport. Studies and Research, 14-27. DOI: 10.1515/pcssr-2015-0002

Sandler, D.M., Shani, D. (1989). Olympic Sponsorship vs. 'Ambush' Marketing: Who Gets the Gold?, Journal of Advertising Research, 29(4), 9-14.

Shani, D., \& Sandler, D.M. (1998). Ambush marketing: is confusion to blame for the flickering of the flame?, Psychology \& Marketing, 15(4), 367-383.

Wolfsteiner, E., Grosh, R., Wagner, U. (2015). What Drives Ambush Marketer Misidentification?, Journal of Sport Management, 29, 137-154. http://dx.doi.org/10.1123/JSM.2014-0122. 
AUTHOR'S ADDRESS: Monika Piątkowska

Józef Pilsudski University of Physical Eucation in Warsaw

Department of Organisation and History of Sport

Marymoncka 34

00-968 Warsaw

Poland

E-mail: monika.piatkowska@awf.edu.pl

Received: 6 September 2016; Accepted: 14 November 2016 